\title{
ON THE USAGE OF OLD AND MODERN TECHNOLOGIES FOR ECONOMIC SUSTAINABILITY
}

\author{
MARIAM JIBUTI \\ Dr., Invited Professor, \\ Ivane Javakhishvili Tbilisi State University, Georgia \\ mariami.jibuti382@eab.tsu.edu.ge
}

\begin{abstract}
Research covers the study of old technologies and approaches towards sustainable building, plant/tree medicines and non-timber forest products, ways of maintaining water purity and harvesting rainwater, urban farming and energy efficient lifestyle. Implementing these techniques into the framework of our society, will cause an economic awakening. A shifting to new realizations that the current stream contains much waste and unproductivity, which can change by harmonizing old and new technologies. Knowing how to apply these in modern life, is essential for the ecological economic growth of the future. It is a way of thinking, within all sectors, to enhance not only peoples' daily lives and atmosphere, but the self-reliance and health of the nation itself.

The study highlights the importance of the art of building with stone for sustainable housing and tourism development; while the usage of trees and herbs provides not only healing benefits but also business opportunities. The health of the country is as good as the purity of its water, in so many places there is little or no water, when the rain water provides an abundance of this vital source, but only when it can be collected and stored by proper facilities. Urban farming connects the new generation back to nature and gives knowledge of food production within industrialized society. With the mentioned tools, we can set an ever-increasing long-term goal to sustainable economic growth.

This work was supported by Shota Rustaveli National Science Foundation (SRNSF) (PHDF-18-627, Spatial-Territorial Planning and Economic Development Opportunities of Regions).
\end{abstract}

\section{KEYWORDS: OLD TECHNOLOGIES; SUSTAINABLE BUILDING; URBAN FARMING; ECONOMIC DEVELOPMENT.}

For citation: Jibuti M. On the usage of old and modern technologies for economic sustainability, Globalization and Business, №11, 97-100. https://doi.org/10.35945/gb.2021.11.013

The overall sustainability of a city is encouraged and marked by its relation to its roads, harmony with nature and its structural organization. Tbilisi continues to inwardly expand centrally, why, we must ask are the high-rise multi-story buildings continuing to be built, in close proximity to each other, with placement all around existing multi-story living apartments? When it can be observed that there is a large traffic congestion of the inner cities network of roads. And that there is a continual overflow of traffic from the main roads being overwhelmed. Then there must be conscious well thought out implementation to alleviate this problem. This is due in part to bad long-term planning, as well as continual apartment projects placed in already overcrowded areas with narrow roads and minimal parking. This perpetual trend only causes more and more stagnation and less space for traffic flow for economic growth. The more time spent in traffic contributes to the overall slow down of productivity and much wasted time and money. This stagnation causes also depression and decreased work ethic among those daily affected by this overcrowding. Also, the air is polluted more and more with the increased density and slowing traffic.

A city needs to breathe, it needs to have an ebb and flow, so that it is not clogged up and progress halted; if a city cannot breathe when the signals of ossification abound all around, and there is little interest in developing its outer rings and expanding its natural order, then already the inner rings will start to whither and decay, with the stress and strain of the central core no longer able to keep up with the growing demand and commute. Christopher Alexander writes "The purpose of all architecture is to encourage and support life-giving activity, dreams, and playfulness. But in recent decades, while our buildings are technically better--more stur$d y$, more waterproof, more energy efficient-- they have also become progressively more sterile, rarely providing the kind of environment in which people are emotionally nourished, genuinely happy, and deeply contented" (Alexander, 2005). It is shown how the environment affects people, for people can be too far removed from nature and environment of green and land that they mentally are exhausted, weighed down in the overbearing concrete walls with less and less of 
green and fresh air. Ancient Rome was laid out in patterns, this old technology of geometrical design can help alleviate our cities today. To allow nature to expand within the current framework, by planting trees where possible, and encouraging more green spaces to align with the ever-expanding concrete structures. The Roman roads were lined with trees and beautiful artworks which gave a calm soothing ambience to the passersby. What mosaic landscape do developers and city councils for regional development consider when approaching this topic of natural harmony? The Romans integrated in their design an architecture of strength and enduringness to last centuries, for the people were stronger than those of today, and had more time to admire and be at unity with the beauty they created. We can learn from their approach.

Not only can this be seen in the traffic systems and architectural framework of the city of the leaving behind of the natural landscape but also in the agricultural and horticultural occupations and endeavors of the countryside. In the urge to build is the devastation of the natural order and a schism between nature and city when the two should be interlaced. With each succeeding generation, the young adults get further and further into modern technology but leave behind the old ways of agricultural knowledge and living in harmonious interaction with nature. How long can this persist without dire consequences which reach all facets of society. And so here we are staring into this space, there are implementations to consider such as geometrical layout of new green eco villages, natural architecture, sustainable energy, herbalism, rainwater catchment systems, vertical gardening, water purification etc.

Rainwater catchment systems provide an important benefit for resource conservation. Tbilisi faces ever increasing water disruptions in multiple zones of the city. This is due in part to old pipes breaking down in need of disrepair, which is bound to occur more and more in the coming years, as well as new development and a continual overcrowding of the existing old systems. The questions must be asked what if there were ever water shortages here for extended periods of time? Or in other cities throughout Georgia, this problem exists not only in the city but also in the countryside as many rivers have overtime been diverted and dams built for energy projects like up in Svaneti. In Australia and New Zealand many people have these water catchment systems in place. Research would need to be conducted to see how much rainfall occurs in what parts of the country. This would help alleviate the strain on house to house or flat to flat consumption. Rainwater catchment systems have been in place for thousands of years in Asia, the Middle East, China and India. The Romans were masters at harvesting and storing water and their towns and villas reflect this. Thousands of large cisterns for rainwater storage have been in existence for many centuries around the Mediterranean and North Africa, some are still in use today in Egypt. Turkey also has many of the largest cisterns in the world for holding water. In western Europe, records show that in Venice and other cities rooftop collection and storage of rainwater was the main source of water for 1300 years up to the sixteenth century. "The rapid expansion in use of rainwater catchment systems technolo- gy worldwide has coincided with a period of growing interest in community-based, grassroots, self-help development." (Gould, D., Nissen-Petersen E., 1999).

Because there is less and less water available in the ever-global market it is wise to develop this ancient technology of harvesting and collecting water for personal use. Not only should we encourage the production and development projects with these systems put in place but also the returning of communities and villages back to independent wells with a better communal understanding of water purification and how to cleanse and maintain their individual systems. The main municipal water systems are overburdened and over chemically treated in the increasingly over populated cities of the modern world. When water is carried so far by pipes that it picks up many metals along its route and systemic system leaks overtime and metal decay and or plastic leakage. Jobs must be created in an organic context from the countryside, so that the outflow of population to the big cities is not so constant and to put a cap on the number of inhabitants within a city's inner dwellings. This allows for other regions to develop and smaller villages to not die out from low population counts. But does this water contain the life energy of the water in nature or is it dead water without the pure oxygen? As overpopulation in the city has a tendency to overflow to all aspects of the society, burdening the environment, it is better to develop out than overwhelm the interior; to instead revive the outer villages and countryside so there is an organic link between countryside and city, between farm and market.

Water purification is even more important than the water storage itself. Because if the water is not usable it is unfit for storage. There are ancient ways much healthier than many of the chemically treated methods in which water is "purified" today. Water is the giver of life and must be protected for the adequate nourishment and health of humanity. In the ancient Sanskrit medical texts of the Ayura Veda, "it is directed to heat foul water by boiling and exposing to sunlight and by dipping seven times into a piece of hot copper, then to filter and cool in an earthen vessel". (Baker. 1981) Also the keeping of water in copper vessels is recorded as well as filtering through charcoal and various types of sand and gravel. Copper was regarded as a disinfecting agent in ancient India. There has been research coming forward that the harmful chemicals found in water and for water treatment are a major source of disease and cancer. The older methods of water purification and storage can give us renewed health and vigor.

Ancient technology of building materials and usage of green energy can help with expensive housing costs in both city and rural villages for both natural and modern design and also for better environmental outcomes. Earth materials can be used to build housing using raw materials like straw-bale, rammed earth, adobe and clay. We must ask all of this over processing of building materials is it really necessary? When nature provides so much in many places of the world. The caves of Vardzia were vast living spaces of ecological thought etched into the rock. Here high up in the cliffs people lived in the mountain itself, providing a very nourishing environment. Not only here but also in Turkey, China, and many other places of the world there are remains of caves and natural dwell- 
ings built into the landscape both of stone and earth. In Iran there are many cities that were built almost entirely of earth such as Yazd. On the Iranian plateau lies the city of Yazd, it lies close to the ancient Silk Road. The way this ancient city was constructed is of earthen architecture is a living witness to the use of limited resources for building materials. Re-education in the use of these types of building with earth and clay and natural green elements will provide not only new jobs but new elemental landscapes to various regions of the world with expensive housing. Traditional adobe houses are made from the earthen bricks that have dried in the sun and are laid in courses to form walls. Both adobe and rammed earth are made from soil and are therefore truly sustainable and provide cheaper alternatives than the expenses of mainstream modern building materials.

In Iran wind catchers were also used to cool down the inner dwellings by means of high towers with windows where the wind could flow down to the corridors below. Such means of air conditioning is environmental and works in harmony with nature than against it. Also, ancient civilizations and even in modern times used root cellars to store their vegetables and food without the need for refrigerators. Surely there are much more efficient ways of keeping food cold, washing clothes, clothes drying, and electric or gas cooking. Solar cooking has been around for centuries, using the rays of the sun to cook food. Also, the use of solar dehydrators for food preservation throughout winter or famines. There could be vast areas of food by the planting of trees and orchards throughout the country, creating free food on the sides of the road, wherever people travel. If apartments and flats had more integrated green houses and areas for growing vegetables, fruits, herbs, and plants, this creates more connection to the land. This brings forth much more abundance, than importing food from far away countries using large amounts of fuel and energy, instead of sourcing local production and or free food areas. As for nature also needs to be returned to its proper place as the healer instead of the pharmacy alone. The pharmacies of old were using vast amounts of natural plants and herbs to heal people. Whereas today much of these chemicals contain harmful substances and use quite energy consumption in their manufacturing process. When instead vast fields of herbs and flowers could be cultivated for the healing of the sick and the health of the nations.

People and children in education should be inspired to create their own home herbs and vegetable gardens, to plant trees, to live sustainably in order to preserve the society in which they live. They are custodians of the future, by the example set before them, much can be done in these areas for improvement. We have before us an open door to change our societies for the betterment of human development and health by the technologies and innovations we use from daily use. We can learn from the ancients in their craftsmanship and skill, earth architecture, solar designs, housing, medicines, agricultural and handicrafts. Not everything should be shipped on a boat and imported from far away, when you can get right in your local market or countryside village. We are at a crossroads; we cannot sustain this current trend of consumption with pollution unchecked. We must change course and consciously think about these things more intently with vision because there is devastating consequences if we do not. This is a call to return to nature to have cities and societies that are built in a green ecological way with ancient technology and clean living. This is a pathway we should strive to go down. With every tree planted, with every breathe taken let us renew the way we see the greenery around us as living within nature than nature outside us.

\section{REFERENCES:}

Alexander, C., Ishikawa S., Silverstein M., (1997). A Pattern Language: Towns, Buildings, Construction, Oxford University Press, New York

Allen, W.E.D., (1971). A History of the Georgian People, Barnes \& Noble; Reprint edition

Bajer, M.N., (1981). The Quest for Pure Water, American Water Works Association,

Bedianashvili, G., (2017). Formation of Knowledge Economy and Innovative Entrepreneurial Policy: Institutional Aspects. Globalization and Business, 3, 10-17.

Bedianashvili, G., (2018). Culture as a Factor of Knowledge Economics with Paradigmatic Changes in Systemic Institutional Context. Globalization and Business, 6, 58-66.

Bonsall, W., (2015). Will Bonsall's Essential Guide to Radical, Self-Reliant Gardening: Innovative Techniques for Growing Vegetables, Grains, and Perennial Food Crops with Minimal Fossil Fuel and Animal Inputs, Chelsea Green Publishing

Bragg, P.C., Bragg P., (2014). Water, Health Science, California

Bubel, M., Bubel N., (1991). Root Cellaring Natural Cold Storage of Fruits and Vegetables, Storey Publishing, Massachusetts

Buhner, S. H., (2002). The Lost Language of Plants the Ecological Importance of Plant Medicines to Life on Earth, Chelsea Green Publishing, Vermont

Cornell, T., Matthews J., (1982). Atlas of Roman World, Checkmark Books

Fell, D., (2011). Vertical Gardening Grow Up, Not Out, For more Vegetables and Flowers in much less Space, Rodale Inc., New York Fritchey, P., (2004). Practical Herbalism Ordinary Plants and Extraordinary Powers, Whitman Publications, Indiana

Fukuoka, M., (2009). The One-Straw Revolution: An Introduction to Natural Farming, NYRB Classics

Gould, D., Nissen-Petersen E., (1999). Rainwater Catchment Systems for Domestic Supply, Intermediate Technology Publications, London 
Jibuti, M., (2019). Administrative Division, Regions of Georgia and their Characteristics, Globalization and Business, \#8:126129. https://doi.org/10.35945/gb.2019.08.016

Jibuti, M., (2020). Convergence and Growth-Conflicting Goals of Economic Policy-A Case Study of Georgia. Environmental \& Socio-economic Studies. https://doi.org/10.2478/environ-2020-0001

Johnson, D., Gibson, S., (2008) Green from the Ground Up Sustainable, Healthy, and Energy-Efficient Home Construction, Taunton Press, Inc., Connecticut

Keshelashvili, G., Jibuti M., (2020). Anti-crisis Economic Plan of the Government of Georgia and Business Challenges during Coronavirus. Conference Proceedings, Ivane Javakhishvili Tbilisi State University Paata Gugushvili Institute of Economics.

Kharaishvili, E., Natsvlishvili I., (2020). Food Safety Challenges in Georgia and Agricultural Development Priorities in the Post-Coronavirus Period. Conference Proceedings, Ivane Javakhishvili Tbilisi State University Paata Gugushvili Institute of Economics.

Kharbedia R., (2018). Economic Problems or Crisis of Economic Science. Globalization and Busines, 6, 81-85.

McRaven, C., (1997). Stonework: Techniques and Projects, Storey Publishing, LLC; 11th Printing edition

Mekvabishvili, E., (2019). The Economic Role of the State in Conditions of Globalization, Globalization and Business, \#8, pp. 22-33. https://doi.org/10.35945/gb.2019.08.002

Papava, V., (2019). Politicization of the Economy and Non-Economic Policy (Experience of Post-Communist Georgia), Globalization and Business, \#8:13-21. https://doi.org/10.35945/gb.2019.08.001

Papava, V., (2020). On the Reflection of Coronomics in Economic Science and Economic Policy. Globalization and Business, 10, 15-24. https://doi.org/10.35945/gb.2020.10.001

Smith, S., (2000) Greenhouse Gardener's Companion Growing Food and Flowers in Your Greenhouse or Sunspace, Fulcrum Publishing, Colorado

Stone, C., (2015). The Urban Farmer: Growing Food for Profit on Leased and Borrowed Land, New Society Publishers 